\title{
Slab temperature control on volatile budgets of arc magmas tracked from melt inclusion halogen contents
}

\author{
RAIMUNDO BRAHM ${ }^{1}$,TAKESHI KURITANI ${ }^{2}$, NAOYA \\ SAKAMOTO $^{3}$, HISAYOSHI YURIMOTO ${ }^{3}$, GEORG F. \\ ZELLMER $^{1}$, Mitsushiro NAKAGAWA ${ }^{2}$, EIICHI SATO ${ }^{4}$ \\ ${ }^{1}$ Volcanic Risk Solutions, School of Agriculture and \\ Environment, Massey University, Private Bag 11 222, \\ Palmerston North. (r.brahm@massey.ac.nz) \\ ${ }^{2}$ Graduate School of Science, Hokkaido University, Sapporo, \\ 060-0810, Japan. \\ ${ }^{3}$ Isotope Imaging Laboratory, Creative Research Institution, \\ Hokkaido University, Sapporo, 001-0021, Japan. \\ ${ }^{4}$ Higher Education Development, Osaka Prefecture \\ University, Osaka, 599-8531, Japan
}

The main engine of magma genesis in subduction zones is the volatile release from the subducted slab into the overlying mantle wedge. Volatiles like $\mathrm{H}_{2} \mathrm{O}$ and halogen elements are mainly transported in hydrous mineral phases (e.g., amphibole, serpentine, chlorite), which are carried in the hydrated lithospheric mantle, altered MORB and sediment cover layers of the slab. There is still much debate on the processes involved during slab-fluid release (slab dehydration or melting) and the nature of the fluid (aqueous, supercritical or silicate liquid). Halogen elements ( $\mathrm{F}$ and $\mathrm{Cl}$ ) have the potential to track slab dehydration and fluid-flux melting processes, as they are not easily partitioned during early magmatic differentiation processes. In addition, the contrasting partioning behaviour of $\mathrm{F}$ and $\mathrm{Cl}$ between hydrous minerals and fluids/melts can assist with the identification of the controlling processes and mineral phases involved during volatile release from the slab.

Primary magma contents of $\mathrm{F}$ and $\mathrm{Cl}$ where obtained from olivine-hosted melt inclusions from seven volcanic systems along and across the arc in northern Japan. Following pre- and post-entrapment corrections, arc front volcanoes show coupling behaviour of $\mathrm{F}$ and $\mathrm{Cl}$, suggesting that the mineral phases and volatile release processes are similar for all arc volcanoes in this area. A positive relationship between the halogen concentration and slab surface temperature below each volcano was identified, indicating slab temperature control on the abundance of volatiles in primary arc magmas. Conversely, in the back-arc $\mathrm{F}$ is generally enriched over $\mathrm{Cl}$, with higher $\mathrm{F} / \mathrm{Cl}$ ratios found in volcanic systems situated at greater distance from the trench. The contrasting behaviour of halogens between arc-front and back-arc volcanoes can be linked to a change in the volatile release process, from dehydration in the arc to melting in the back-arc. 